\title{
ARCAÍSMOS Y NOVEDADES EN EL PANORAMA SEÑORIAL DE LA COMARCA DE SALAS DE LOS INFANTES SEGUN EL BECERRO DE LAS BEHETRÍAS*
}

\author{
Julio Escalona Monge**
}

El Ilamado Libro Becerro de las Behetrías ${ }^{1}$ es una fuente fundamental para conocer la estructura señorial de la Castilla al norte del Duero a mediados del siglo XIV. También lo es para comprender los procesos que estaban en marcha en etapas anteriores y cuyas consecuencias se expresan en sus registros. La enorme potencialidad del Becerro como instrumento de análisis retrospectivo es generalmente reconocida desde los trabajos de Ferrari, así como el hecho de que la situación que se perfila a través de sus datos presenta no pocos trazos de arcaísmo, que remiten a etapas anteriores ${ }^{2}$. Este carácter arcaizante del Becerro ha sido reiterado, hasta convertirse en un tópico historiográfico de cierta recurrencia. No todo es arcaico en el Becerro, sin embargo. Un análisis detallado muestra que elementos de evolución lenta se entremezclan con otros más coyunturales $y$, en definitiva, lo que tenemos es una mezcla de arcaísmos y

* Una primera versión de este trabajo fue presentada en 1992 a las IV Jornadas Burgalesas de Historia. Burgos en la Baja Edad Media.

** Departament of History. University College London.

1. Edición de MARTÍNEZ DíEZ, G., Libro Becerro de las Behetrías. León 1981. A lo largo de todo el trabajo, citaré los epígrafes del Becerro de acuerdo con el sistema más extendido, consistente en abreviar la obra como LBB y añadir el número de Merindad en romanos y el número de localidad en arábigos.

2. Especialmente en FERRARI, A., "Testimonios retrospectivos sobre el feudalismo castellano en el Libro de las Behetrías", Boletín de la Real Academia de la Historia, 172, (1975), pp. 7-119 y 281-404; y FERRARI, A., "Arcaísmos tópicos del reino astur testimoniados en el Libro Becerro de las Behetrías", Boletín de la Real Academia de la Historia, 175, (1978), pp. 215-307 y $314-493 ; 176,(1979)$, pp. 175-244 y 245-308; 177, (1980), pp. 613-670 y 207-288; 178, (1981), pp. 1-56. 
novedades que refleja fielmente la naturaleza dialéctica de los procesos de cambio histórico. Voy, pues, a trabajar a partir de la confrontación de las nociones de arcaísmo y novedad. Por la primera entenderé un rasgo presente en el momento de redacción del Becerro, pero originado en una etapa anterior y diferente, en la cual este rasgo tenía una lógica funcional que puede haberse mantenido, haber cambiado o haber desaparecido a la altura de 1352. Con ello no quiero decir que los rasgos arcaicos -altomedievales, por ejemplo- carezcan de lógica o funcionalidad a mediados del siglo XIV, pero sí que la lógica de su presencia se remonta a etapas anteriores y que su mera perduración constituye una pre-condición para los desarrollos de origen más reciente. Al hablar de novedad, me referiré a un rasgo de implantación relativamente reciente en la zona de estudio (ya se verá más adelante si se puede precisar cómo de reciente).

En este trabajo pretendo explorar la dialéctica entre arcaísmos y novedades aplicada al análisis de la imagen que el Becerro de las Behetrías nos transmite de un espacio comarcal: el amplio sector al sudeste de Burgos, desde Juarros a la Tierra de Pinares, que en los siglos XII y XIII pertenecía al alfoz de Lara y otras demarcaciones colindantes, como Ausín o Juarros. ${ }^{3}$ Sobre este espacio trataré de distinguir las situaciones consolidadas desde antiguo de las surgidas con posterioridad, a través de tres ejes: modalidades señoriales; implantación de los diferentes linajes nobiliarios representados y estructuras de articulación territorial. ${ }^{4}$

a) Desde el punto de vista de las modalidades señoriales, es bien sabido que el Becerro clasifica los diferentes lugares de acuerdo con cuatro categorías fundamentales -behetría, solariego, abadengo y realengo- o combinaciones de ambas. En los últimos años se han ido acumulando trabajos sobre las behetrías

3. Una introducción al territorio sobre el que se proyecta esta investigación puede verse en ESCALONA MONGE, J., "Análisis de las estructuras territoriales del Condado de Castilla: perspectivas de investigación", I Jornadas Burgalesas de Historia Medieval. Introducción a la Historia de Burgos en la Edad Media. Burgos 1990, pp. 541-555. He analizado exhaustivamente la trayectoria medieval del sector en mi Tesis Doctoral: ESCALONA MONGE, J., Transformaciones sociales y organización del espacio en el alfoz de Lara en la Alta Edad Media, Tesis inédita, Universidad Complutense 1996. Las líneas esenciales de este trabajo aparecerán publicadas en ESCALONA MONGE, J.: Sociedad y territorio en la Alta Edad Media castellana. La formación del alfoz de Lara, (en preparación). Las citas sucesivas las referiré a esta publicación, aunque sin expresar paginación.

4. La imagen que el Becerro de las Behetrías proporciona del antiguo alfoz de Lara y sus territorios limítrofes está lastrada por dos ausencias: el burgo de Santo Domingo de Silos, con sus aldeas inmediatamente anejas, y las villas de Lara y Barbadillo del Mercado -junto con La Revilla - las cuales estaban a mediados del siglo XIV bajo la jurisdicción del Concejo de Burgos, ausente en el Becerro (ver Martínez Díez, Libro Becerro de las Behetrías, t. 1, pp. $76-77$ y t. II, pp. 589 y ss.). No cabe duda de que estas lagunas son una rémora para cualquier estudio. Sin embargo, el resto del territorio serrano presenta una imagen sumamente interesante y que permite una aproximación a los procesos de cambio que estaban teniendo lugar en el territorio del antiguo alfoz de Lara. 
castellanas, que han puesto de manifiesto que estas cuatro modalidades señoriales se definen como tales a través de un lento proceso que culmina a fines del siglo XII. ${ }^{5}$ Todas ellas parecen proceder de las estructuras de poder propias de la Alta Edad Media, cuya transformación tiene lugar durante los siglos $X$ y $\mathrm{XI}$, pero de las cuatro es la behetría la que se mantiene más próxima al universo de relaciones sociales altomedievales. En este sentido, y a pesar de haber nacido como tal durante el siglo XII, la behetría puede ser entendida como un rasgo de arcaísmo -si se quiere, la manera en que se expresa el arcaísmo de la sociedad castellana del siglo XII- en tanto en cuanto constituye una modalidad de ejercicio del poder más difusa y participativa que formas más rotundamente feudales, como el abadengo y el solariego.

La behetría, en sus formulaciones más acabadas presenta dos niveles de ejercicio del señorío, constituido el primero por un conjunto de diviseros que, si en términos evolutivos pueden ser identificados con los grupos de personajes destacados de las comunidades altomedievales, a la altura del siglo XII estaba siendo copado de manera casi generalizada por miembros de la nobleza castellana; el segundo nivel, el del señorío singular es una modalidad especial de poder señorial, muy ligado a la superior potestad regia y que pudo derivar del ejercicio de señorío sobre las demarcaciones territoriales supralocales -los alfoces- de la Alta Edad Media. ${ }^{6}$ Se trata de un dominio señorial que se superpone al de los diviseros y coexiste con él. El señorío singular sobre behetrías se muestra desde un principio vinculado a los linajes nobiliarios más poderosos y llegará a constituir una de las señas de identidad política de los principales linajes castellanos. ${ }^{7}$

En definitiva, se puede decir que la manera en que se ejercía mayoritariamente el poder señorial en la Castilla plenomedieval, expresada en el señorío de behetría, estaba plenamente enraizada en una red de relaciones de naturaleza arcaizante que actuaban como un potencial limitador del poder señorial. Ahora se empieza a entrever que el crecimiento de los poderes feudales en Castilla se canalizó sobre todo a partir del desarrollo de la behetría, en términos cuantitativos, pero cualitativamente otras formas señoriales más "típicamente" feudales, como el solariego y, sobre todo, el abadengo pudieron tener un peso mayor en la definición de la clase feudal como tal. No puede ser extraño que

5. Ver ESTEPA, C., "Estructuras de poder en Castilla (siglos XII-XIII). El poder señorial en las merindades burgalesas", III Jornadas Burgalesas de Historia. Burgos en la Plena Edad Media. Burgos 1994, pp. 245- 294 y ÁLVAREZ BORGE, I., Poder y relaciones sociales en Castilla en la Edad Media. Los territorios entre el Arlanzón y el Duero en los siglos X al XIV. Valladolid 1996, pp. 283 y ss.

6. Ver ESCALONA, J., "Unidades territoriales supralocales: una propuesta sobre los orígenes del señorío de behetría", en ESTEPA, C.; JULAR, C. (Coords.). Los señoríos de behetría, (en prensa).

7. ÁLVAREZ BORGE, I., "Nobleza y Señoríos en Castilla la Vieja meridional a mediados del siglo XIV", Brocar, 21, (1997) 55-117. 
la competencia entre los diferentes poderes señoriales laicos actuase simultáneamente en dos sentidos: a) dentro del universo conceptual de las behetrías, intentado acaparar divisas en lugares $y$, sobre todo, ganar el señorío singular sobre ellas ${ }^{8}$; b) promoviendo otras formas señoriales y propiciando así la transformación de las behetrías hacia el solariego o abadengo. Este proceso es muy antiguo; de hecho puede haber estado actuando sobre las comunidades locales y supralocales castellanas incluso antes de que la behetría tal y como la conocemos hiciese su aparición, especialmente por medio de la difusión del señorío eclesiástico en los sigos X y XI. Desde luego estaba en pleno auge a fines del siglo XII, cuando la Curia de Nájera intentó inútilmente "fosilizar" el panorama señorial prohibiendo que unas categorías señoriales fuesen transformadas en otras. ${ }^{9}$ En los siglos posteriores, el proceso continuó, dando lugar al panorama del Becerro de las Behetrías, donde la behetría representa a grandes rasgos un $25 \%$ frente a otras modalidades señoriales. Sabiendo que la tendencia histórica había sido durante al menos doscientos años el paso de behetría a otras modalidades -nunca a la inversa-, es fácil imaginar la importancia cuantitativa que la behetría tuvo que tener en la Plena Edad Media. ${ }^{10}$

Pero la conversión de behetrías en otras formas señoriales operó a través de complejos procesos en los que los dos niveles señoriales de las behetrías pudieron jugar un papel decisivo. Cuando el nivel del señorío singular predomina, se puede pensar en transiciones de behetría a solariego o abadengo en favor de un sólo señor; en cambio, cuando predomina el nivel de los diviseros y la transformación se produce gradualmente, es más fácil que emerjan formas mixtas, de las cuales las más corrientes serán el solariego compartido por muchos señores y el condominio de abadengo y solariego. ${ }^{17}$

Es bien sabido que la confección del Becerro de las Behetrías tiene su origen precisamente en ese proceso de transformación de behetrías en solariegos. A mediados del siglo XIV la coyuntura política y de competencia intranobiliaria dio lugar a un intento por amortizar las behetrías por medio de una decisión política. ${ }^{12}$ Esta iniciativa dio lugar a un intenso debate, puesto que eran muchos

8. Aunque está claro que el señorío singular en lugares de behetría era un factor básico de la identidad de los linajes nobiliarios, aún sabemos poco sobre los mecanismos que determinaban su disfrute. Sin duda la herencia jugaba un papel crucial, como también lo hacía el favor regio, pero queda mucho que investigar sobre otros factores como el disfrute de tenencias sobre demarcaciones amplias, la importancia del arraigo patrimonial en un sector determinado y el peso de las relaciones clientelares y vasalláticas. Sobre este último aspecto véanse las sugerencias planteadas por JULAR PÉREZ-ALFARO, C., 'Familia y clientela en dominios de behetría a mediados del siglo XIV', en Casey, J.; Hernández Franco, J., eds.: Familia, parentesco y linaje. Historia de la Familia. Una nueva perspectiva sobre la sociedad europea. Murcia 1997, pp. 63-75.

9. Álvarez Borge, Poder y relaciones sociales..., pp. 270 y ss.

10. Estepa, "Estructuras de poder...", pp. 151-153.

11. Escalona, "Unidades territoriales supralocales..."

12. Sobre el proceso que lleva a plantear la supresión de las behetrías y su compleja trama política y social, ver CLAVERO, B., "Behetría 1255-1365. Crisis de una institución de señorio y 
los intereses afectados; no cabe duda de que constantemente estaban teniendo lugar fenómenos puntuales de conversión de behetrías en solariego, pero transformarlas de un plumazo hubiera supuesto un cambio sustancial en el delicado equilibrio de poder dentro de la esfera aristocrática, razón por la cual la iniciativa no prosperó, si bien la paulatina amortización de behetrías no sólo no se detuvo, sino que experimentó un notable impulso después de la guerra civil, con la difusión del mayorazgo.

b) En cuanto a los linajes nobiliarios actuantes en la zona de estudio, es preciso destacar que el siglo XIV es un período claramente transicional, durante el cual se va consolidando un proceso secular de retroceso del poder del linaje originario de la comarca, los Lara. A comienzos del siglo XII, la comarca serrana era un bastión del poder de la familia de Lara, y había conocido una expansión territorial notable en dirección a la Tierra de Pinares soriana. ${ }^{13}$ Sin embargo, una serie de factores contribuyeron a modificar esta situación. Por una parte, el crecimiento de los Lara hacia la cúspide de la nobleza castellana les llevó a forjar relaciones patrimoniales, clientelares y de parentesco en una escala mucho más amplia, por lo que el solar de Lara fue quedando cada vez más como un referente ideológico para la familia, pero los verdaderos núcleos de su poder estaban en otros espacios. ${ }^{14}$ Los últimos tenentes de Lara, a fines del siglo XII y en la primera mitad del XIII, ya no seran miembros del linaje de Lara, sino de otros linajes vinculados a ellos, como los Guzmán. ${ }^{15}$ Por otra parte, poderes diferentes fueron infiltrándose en la zona. Para empezar, los monarcas, desde Alfonso VII desempeñaron una política de control de ese territorio - en abierta confrontación al principio con los Lara- favoreciendo para ello el desarrollo de fuertes entidades monásticas como San Pedro de Arlanza y, sobre todo, Santo Domingo de Silos, que conoció una expansión notable desde tiempos de Fernando I hasta su alzamiento como cabecera de la Merindad de Santo Domingo de Silos en el siglo XIII. ${ }^{16}$ La expansión

de la formación de un derecho regional en Castilla", Anuario de Historia del Derecho Español, 44, (1974), pp. 201-342; ÁLVAREZ BORGE, I., El feudalismo castellano y el libro Becerro de las Behetrías: La Merindad de Burgos, León 1987, pp. 13-33 y ESTEPA, C., "Las behetrías en el Canciller don Pedro López de Ayala", LORING, M. I., ed., Historia social, Pensamiento historiográfico y Edad Media. Homenaje al Prof. Abilio Barbero de Aguilera. Madrid 1997, pp. 95-114.

13. Escalona, Sociedad y territorio...

14. Sobre el desarrollo del linaje de Lara, ver DOUBLEDAY, S., The Laras. An aristocratic family in the kingdoms of Castile and León (1075-1361), Tesis Doctoral reprografiada, Universidad de Harvard, Cambridge, Massachussets 1996. Sobre el impacto de este desarrollo en la zona de Lara, ver Escalona, Sociedad y territorio...

15. ÁLVAREZ BORGE, I., Monarquía feudal y organización territorial. Alfoces y merindades en Castilla (siglos X-XIV), Madrid, 1993, pp. 131-133.

16. Ver ÁLVAREZ BORGE, I., "Merindades y merinos menores de Silos, Muñó y Castrojeriz. Notas sobre la evolución de la monarquía feudal y la organización territorial en Castilla (1200-1350)", III Jornadas Burgalesas de Historia. Burgos en la Plena Edad Media. Burgos 1994, pp. 655-676. Sobre los señorios eclesiásticos de la zona, ver Álvarez Borge, Poder y relaciones sociales..., pp. 109 y ss. y 173 y ss. 
del abadengo en el siglo XII dió lugar a la aparición de un "pasillo monástico" cerrando el territorio por el suroeste por medio de los cotos de Covarrubias, Arlanza y Silos. Este último se hizo con el control de los pequeños alfoces de Ura, Tabladillo y Huerta, mientras Arlanza llevaba a cabo una notable expansión en el sector suroriental -sector de San Leonardo de Yagüe- y en la Tierra alta de Pinares -Regumiel, Canicosa, Vilviestre, etc. ${ }^{17}$ Ya en el siglo XIII, la expansión de la Tierra de Soria absorbió Duruelo de la Sierra ${ }^{18}$ y el declive de Lara como centro jerárquico se expresó en dos novedades: la subordinación de Lara al señorío del Concejo de Burgos en $1255^{19}$ y la emergencia de Salas de los Infantes como importante centro regional, vinculado al desarrollo de las rutas de transhumancia ganadera. $^{20}$

En medio de este panorama cambiante, la presencia señorial de los Lara se vio parcialmente reemplazada por otros linajes, entre los que cabe destacar a los Haro y, ya en fechas muy próximas a la redacción del Becerro, los Velasco, un linaje implantado en Castilla Vieja y que a fines del siglo XIII inició una elevación basada en una hábil política matrimonial y en, el desempeño de oficios regios compaginado con la militancia en las luchas intranobiliarias de la primera mitad del siglo XIV. ${ }^{21}$ En la primera mitad del siglo XIV los Velasco son un linaje en pleno proceso ascendente, uno de los casos que permitieron a Moxó establecer su distinción entre "nobleza vieja" y "nobleza nueva". ${ }^{22}$ Esta idea de un reemplazo en la esfera nobiliaria ha perdido actualmente la mayor parte de su potencial explicativo, ${ }^{23}$ pero no cabe duda de que la presencia de los Velas-

17. SPA 140,1213 . Ver Escalona, Sociedad y territorio...

18. Texto en ORTEGO, T., 'Duruelo de la Sierra. Algunas fuentes para su historia', Celtiberia, 32, (1966) pp. 233-237.

19. $\mathrm{CDCB} / 30$.

20. ESCALONA MONGE, J., 'Jerarquización social y organización del espacio. Bosques y pastizales en la Sierra de Burgos (siglos X-XII)', Mélanges de la Casa de Velázquez, (en prensa).

21. Las líneas principales del ascenso de los Velasco han sido tratadas por GONZÁLEZ CRESPO, E., Elevación de un linaje nobiliario castellano en la Baja Edad Media: los Velasco; Madrid, 1981; y GONZÁLEZ CRESPO, E., "Los Velasco en el horizonte dominical de la nobleza castellana según el Libro de las Behetrías", Anuario de Estudios Medievales; 14, (1984), pp. 322-343. Investigaciones recientes han permitido profundizar en el conocimiento de los mecanismos de actución de los Velasco y en la trayectoria del linaje antes y durante el siglo XIV: Jular, 'Familia y clientela...; JULAR PÉREŻ-ALFARO, C., 'Dominios señoriales y relaciones clientelares en Castilla: Velasco, Porres y Cárcamo (siglos XIII-XIV)', Hispania, 192, (1996), pp. 137-171; ver también próximamente la contribución de Cristina Jular en Estepa y Jular (Coords.) Los señoríos de behetría, (en prensa). La misma autora está en la actualidad elaborando una amplia monografía sobre este grupo nobiliario.

22. MOXÓ, S., "De la nobleza vieja a la nobleza nueva. La transformación nobiliaria castellana en la Baja Edad Media", Cuadernos de Historia (Anexos a la revista Hispania), 3, (1969), pp. 1-120.

23. Ver PASTOR BAÑOS, R.; ESTEPA DÍEZ, C.; ALFONSO ANTON, I.; ESCALONA MONGE, J.; JULAR PÉREZ-ALFARO, C.; PASCUA ECHEGARAY, E.; SÁNCHEZ LEÓN, P., 'Baja Nobleza: aproximación a la historiografía europea y propuestas para una investigación', Historia Social, 20, (1994) pp. 23-45. 
co en la zona de estudio es, en términos estructurales, una novedad que merece atención, especialmente debido a que el Becerro de las Behetrías recoge la situación inmediatamente anterior a la desaparición de los dos linajes principales del período anterior: los Lara y los Haro. ${ }^{24}$ La desaparición de ambos a mediados del XIV, deja como principal entidad señorial del sector a los Velasco, que en la segunda mitad del siglo consolidan su poder, redondeando sus posesiones, ampliando el solariego y fortaleciendo la unión de linaje y solar a través del mayorazgo. ${ }^{25}$ A la altura de 1352 la presencia de los Velasco en la zona de estudio se concreta en tres focos: los antiguos alfoces de Juarros y Barbadillo y el territorio en torno a Salas de los Infantes. Su posición en cada uno de ellos varía en función de las diferencias entre dichas áreas y de la naturaleza de la irrupción del linaje en las mismas. El análisis comparativo de las tres, como se verá, proporciona claves interesantes para comprender la comarca en su conjunto.

c) Paralelamente a estas transformaciones en la naturaleza del poder feudal y en la composición de los poderes concretos actuantes, desde el siglo XII tiene lugar en el territorio del antiguo alfoz de Lara un proceso de alteración de las centralidades territoriales. El gran alfoz de Lara, tal y como se perfila a fines del siglo XI, es resultante de una expansión del área controlada desde el viejo centro condal, absorbiendo demarcaciones menores vecinas, como el alfoz de Barbadillo y los sectores orientales de Salas y la Tierra de Pinares. Pero desde el siglo XII el centro territorial de Lara tiende a perder fuerza ante la emergencia de nuevos centros: primero será Santo Domingo de Silos, cabeza de la Merindad y luego Salas, que en la Baja Edad Media -bajo el señorío de los Velasco- acabará por hacerse con la centralidad territorial comarcal. ${ }^{26}$ A la altura de 1352, la emergencia del centro territorial de Salas de los Infantes aparece vinculada a la consolidación del ascenso social del linaje Velasco, cuya presencia en la zona es una novedad que se remonta a lo sumo a dos generaciones, a veces a mucho menos, como se verá. Los Velasco aparecen claramente implantados en tres sectores dentro del área de estudio: Salas, Valdelaguna y Juarros.

\section{La comarca de Salas}

Los datos sobre el sector de Salas de los Infantes son sumamente parcos y dispersos. Se ignora prácticamente todo sobre su trayectoria en el siglo $X$ y parece haber quedado absorbido o vinculado al alfoz de Lara en el transcurso de la segunda mitad del siglo $\mathrm{XI}^{27}$ situación que parece continuar en el

24. Sobre la extinción de ambas líneas dinásticas, ver Moxó, "De la nobleza vieja a la nobleza nueva...", pp. 43-44 y 55.

25. CLAVERO, B., Mayorazgo. Propiedad feudal en Castilla (1369-1836). Madrid 1976, especialmente p. 37; Escalona, Sociedad y territorio...

26. Escalona, Sociedad y territorio...

27. En 1094 (CSMC2/226) Juliana Fortúniz, probablemente emparentada con el señor de Lara Gonzalo Núñez, disponía de un palatium en Salas que había pertenecido a su padre for- 
XII. ${ }^{28}$ Hasta fecha tardía no se documenta la existencia de una demarcación en torno a la actual cabeza de Partido Judicial, Salas de los Infantes, ${ }^{29}$ imagen que es también reconocible en el Becerro de las Behetrías. ${ }^{30}$ En el Becerro, los lugares del entorno de Salas ofrecen un cuadro Ilamativamente cohesivo. El

tún Álvarez, probable tío de Gonzalo Núñez. Esto implica la existencia de un palacio señorial en Salas en tiempos de Fernando I, en que Fortún Álvarez aparece como confirmante asiduo en diplomas regios. La presencia señorial de parientes de los Lara coincide con la época en que estas áreas orientales debieron de quedar integradas en el alfoz de Lara (Escalona, Sociedad y territorio...)

28. SPA/113 (1156): “... Notum sit.. quod ego Sancius Rodriz, filius Roderiz Gondisalvi mansueti, dono et confirmo ecclesie Sancti Petri... omnes hereditates meas atque divisas quas in territorio de Lara possideo, scilicet, in Ribella de Fonte et in Palaciolos et in Villa-Momel et in Salas, et Castravido et in Fornellos, et ubicumque invenire potueritis eam liberam possideatis... Et hec hereditas ibi concessa fuit.- Et omne concilium de Salas cf." Se debe manejar este texto con prudencia, porque cita Salas como perteneciente al alfoz de Lara, pero también Revilla de la Fuente, que pertenecía al alfoz de Ausín, por lo que es aconsejable no sacar de él conclusiones muy tajantes en el plano territorial. Escalona, Sociedad y territorio.... Cfr. Martínez Díez, Pueblos y alfoces..., p. 171 y Álvarez Borge, Monarquía feudal..., pp. 90).

29. La primera impresión clara de un distrito de Salas procede del fuero apócrifo supuestamente otorgado por Gonzalo Gustios -el legendario padre de los infantes de Lara-- en 964. El texto del fuero - conocido sólo por una confirmación de Pedro I de 1351 conservada en el Archivo Municipal de Salas de los Infantes- fue publicado por primera vez por Serrano (SPA/96), advirtiendo que se trataba de una falsificación del siglo XII. Posteriormente varios autores se han pronunciado a favor o en contra de la autenticidad del fuero, los más considerándolo una falsificación, si bien no hay acuerdo sobre su fecha. En breve se podrá ver un estudio exhaustivo de este documento en ESCALONA, J.; ALFONSO, I.; AZCARATE, P; JULAR, C.: Falsear el pasado, construir el presente. El monasterio de San Pedro de Arlanza y los fueros falsos de Lara y Salas de los Infantes (Burgos), en preparación. Por ahora, baste decir que, en su forma actual, el texto es una falsificación que encaja perfectamente en el contexto político de 1351; sin embargo, la imagen que ofrece del distrito dependiente de Salas corresponde más bien a la segunda mitad del siglo XIII: In primis do illis hominibus in illa villa [Salas] habitu[rum?] senper de mundo duodecim alcaldes, et consesit illos has villas: Castrovido, Terrazas, Torneros, Facinas, Castriello, Peniella de Cedron, Forniellos, Palaçios, Nava, Aroio, ut veniant ad suum forum. (Transcripción de Pilar Azcárate). Sobre las conexiones entre este documento y las tradiciones legendarias de la comarca serrana se puede ver ESCALONA MONGE; J., "Épicas, crónicas y genealogías. En torno a la historicidad de la Leyenda de los Infantes de Lara", Cahiers de Lingüistique hispanique médiévale, 23, (2000), pp. 113-176.

30. Los lugares del entorno de Salas en el LBB son los siguientes: LBB, XV, 10: Salas de los Infantes: Behetría (Señor singular y natural: Pedro Fernández de Velasco). LBB; XV, 5: Castrillo de la Reina: Behetría (Señor singular: Pedro Fernández de Velasco). LBB, XV, 36: Monasterio de la Sierra: Behetría (Señor singular y natural: Pedro Fernández de Velasco). LBB, XV, 37: Arroyo de Salas: Behetría (Señor singular: Pedro Fernández de Velasco). LBB, XV, 38: Hoyuelos de la Sierra: Behetría (Señor singular: Pedro Fernández de Velasco). LBB, XV, 63: Hornillos: Solariego de Pedro Fernández de Velasco y Diego Pérez Sarmiento por su mujer, María de Velasco. LBB, XV, 71: Palacios de la Sierra: Solariego de do mayor de Castañeda, doña María de Velasco y Pedro Fernández de Velasco. LBB, XV, 24: Castrovido: Solariego de doña Sancha de Haro y Juan Díaz de Rocaful. LBB, XV, 39: Terrazas: Solariego de doña Sancha de Haro y Juan Díaz de Rocaful. LBB, XV, 16: Hacinas: Solariego del monasterio de Fuencaliente (sic), hijos de Juan Martínez de Avellaneda y de la viuda de Juan Martínez de Leyva. 
centro del sector es Salas de los Infantes, behetría cuyo señor es Pedro Fernández de Velasco. En sus inmediaciones hay otras cinco villas de behetría en las que el señor singular es el mismo don Pedro, así como cinco lugares solariegos en dos de los cuales son señores los Velasco y en otros dos los $\mathrm{Haro}$. El abadengo está prácticamente ausente del entorno inmediato, si bien es abundante al sur y al este.

Llama inmediatamente la atención la posición de fuerza del linaje Velasco en este espacio. A pesar de que en las cinco behetrías aparecen como diviseros don Nuño de Lara y don Pedro de Haro, ${ }^{31}$ en todas ellas es el Velasco señor singular. En cuanto a los solariegos, dos de ellos pertenecen a miembros del linaje Velasco: Pedro Fernández de Velasco, su hermana doña María y, en una ocasión (Palacios de la Sierra), su madre, Mayor de Castañeda; otros dos pertenecen a Sancha de Haro, viuda de Diego López de Haro, y a Juan Díaz de Rocaful, un personaje muy vinculado a los Haro. ${ }^{32}$ La nota discordante la da Hacinas, solariego compartido por el monasterio de Fuencaliente, los hijos de Juan Martínez de Avellaneda y la esposa de Juan Martínez de Leyva, sin presencia conocida de los Velasco ni los Haro.

Pero, sobre todo, llama la atención que las behetrías del entorno de Salas constituyen una red de prestaciones de carácter territorial. En Salas de los Infantes, Pedro Fernández de Velasco recibe una martiniega de 240 mrs. "por el Palacio de Salas". Este palacio o casa de Salas parece ser una referencia señorial clave, cuyos derechos habían pertenecido antes de Pedro Fernández a Diego López de Haro y aún antes a otros señores. ${ }^{33}$ Esto permite establecer una sucesión: quienes quiera que fuesen esos señores anteriores, Diego López de Haro había sido señor de Salas hasta su muerte en 1350, y después ésta había pasado al Velasco. Pagos semejantes de rentas en favor de Pedro Fernández de Velasco se registran en las behetrías de los alrededores y, a primera vista, se podría pensar que se trata de una renta pagada al señor singular de cada lugar, que es en todos Pedro Fernández. Sin embargo, las entradas de Castrillo de la Reina, Arroyo de Salas y Hoyuelos especifican que se le pagan rentas-que unas veces son denominadas martiniega y otras yantar-por tener la casa de Salas; en el primer caso se anota además que la situación no es nueva, sino una práctica consagrada. ${ }^{34}$ En Monasterio de la Sierra no se alude al centro territorial,

31. Sólo comparten dicha condición con Pedro Fernández de Velasco en dos casos: Salas y Monasterio de la Sierra.

32. Sobre Juan Díaz de Rocaful, ver Álvarez Borge, Nobleza y Señoríos..., pp. 82.

33. LBB, XV, 24 (Salas): "...lieva el dicho Pero Ferrandez del dicho logar por rrazon de martiniega dozientos e quarenta maravedis e estos maravedis lievales de dos annos aca por rrazon del Palaçio del dicho logar de Salas e ante desto dicha martiniega levavala Diago Lopez de Haro e los otros sennores que tenien el dicho palaçio..."

34. LBB, XV, 5 (Castrillo de la Reina): “...pagan más al dicho Pero Ferrandez la martiniega e los otros derechos porque es su sennor e tiene el Palacio de Salas; e que la dicha martiniega e fonsadera del dicho logar siempre lo lieva el sennor". LBB, XV, 38 (Hoyuelos): "Pagan al dicho Pero Ferrandez de Velasco por yantar quarenta e siete dineros por la casa de Salas". LBB, 
pero se consigna que Pedro Fernández cobraba allí yantar por fuerza. ${ }^{35}$ Igualmente, debe consignarse el caso dudoso de Hornillos, lugar solariego de Pedro Fernández de Velasco y Diego Pérez Sarmiento, quien ejerce los derechos de su esposa, María de Velasco, hermana del primero. Aquí se consigna, no obstante el pago de un yantar de $30 \mathrm{mrs}$. a Pedro Fernández. ${ }^{36}$ A pesar de la definición de la villa como solariego, el esquema parece recordar el de las behetrías del sector, donde, independientemente de quiénes sean los diviseros, se pagan martiniegas o yantares al señor de la Casa de Salas. Una hipótesis sugestiva sería considerar que Hornillos había sido behetría hasta muy poco antes $\mathrm{o}$, incluso, que estaba en ese momento en plena reconversión.

Se den bajo la forma de martiniega o de yantar, los pagos a la Casa de Salas parecen ser un tipo de renta que preserva la noción de jerarquía territorial en favor del centro de Salas. Probablemente lo mismo hay que pensar del hecho de que todas las behetrías del entorno tengan por señor singular al señor de la casa de Salas: el ganar la casa de Salas llevaría aparejado el señorío de las behetrías dependientes de ella. Todo parece indicar que esta situación se remontaba hacia atrás más allá del tiempo de Diego López de Haro. Sin embargo, no todo es tan antiguo: el Becerro registra igualmente un pago de $50 \mathrm{mrs}$. "al señor de la Casa de Salas" en Villamiel de la Sierra, ${ }^{37}$ lugar situado muy lejos de Salas y cerca de Lara, abadengo y solariego de la esposa de Juan Rodríguez de Sandoval, Pedro Fernández de Velasco, su hermana y la esposa de Sancho Martínez de Leyva. Se trata de uno de los lugares en que Pedro Fernández participa en solariegos muy fragmentados, pero el insólito pago a la Casa de Salas puede estar reflejando un esfuerzo por vincular Villamiel al núcleo de Salas y favorecer una posición hegemónica del Velasco en el lugar. De ser así, el pago de esta renta sólo podría remontarse a la entrada de Pedro Fernández en el señorío de Salas, es decir, dos años.

Del mismo modo, parece que en el sector de Salas los pagos al centro territorial habían sufrido una cierta evolución. Sólo tributan las behetrías del sector y los lugares solariegos donde tienen intereses los Velasco. Por el contrario, los lugares solariegos de los Haro quedan fuera de esas prestaciones y parece muy razonable pensar que se trata de antiguas behetrías que se convirtieron en solariego durante el período en que Diego López de Haro estuvo al frente de la Casa de Salas, por lo que al acceder al mismo el Velasco quedan fuera de esa red de prestaciones.

XV, 37 (Arroyo de Salas): "Dan a Pero Ferrandez el sobredicho por yantar por la Casa de Salas treynta e quatro maravedis"

35. LBB, XV, 36 (Monasterio de la Sierra): "Lieva el dicho Pero Ferrandez dellos por fuerça por yantar setenta e çinco maravedis".

36. LBB, XV, 63: "Dan por yantar al dicho Pero Ferrandez en cada anno treynta maravedis".

37. LBB, XI, 94. Ver ESTEPA DÍEZ, C., "Organización territorial, poder regio y tributaciones militares en la Castilla plenomedieval", Brocar, 20, (1996), pp. 135-176, esp. p. 147. 
En 1352, Pedro Fernández de Velasco llevaba sólo dos años disfrutando del señorío de Salas, que antes había pertenecido a Diego López de Haro. No está claro por qué vía se transmite el señorío sobre Salas, prácticamente indocumentado hasta poco antes. Los Haro son en principio un linaje ajeno a la comarca de Lara, donde el predominio señorial correspondía tradicionalmente a los Lara y a linajes emparentados como los Guzmán. Dos referencias pueden servir de hipótesis: la primera sería la posición de fuerza disfrutada por los Haro a fines del siglo XIII gracias al matrimonio de Diego López de Haro con la infanta Violante, hija de Alfonso $X,{ }^{38}$ lo que pudo haber favorecido su obtención de la Casa de Salas; la segunda serían los entronques entre Laras y Haros, con un caso lejano en el matrimonio de Diego López de Haro "el Bueno" con María Manrique de Lara, en los inicios del siglo XIII, y otro próximo en el de Juan Núñez de Lara III con María de Haro. Pienso que los matrimonios podrían explicar la frecuentísima presencia en el Becerro de los señores de Lara y Haro (don Nuño y don Pedro) compartiendo la condición de diviseros, cosa que se da de manera generalizada en el sector de Salas. En cambio, sospecho que estos cambios en el disfrute del señorío singular de Salas y sus behetrías pueden estar más ligados al favor regio. ${ }^{39}$

En este sentido, es necesario considerar otro hecho crucial: en 1352 Pedro Fernández de Velasco era un joven, bajo la directa influencia de su madre, Mayor de Castañeda, viuda de Fernando Sánchez de Velasco desde ca. $1344 .{ }^{40}$ Todo parece indicar que los derechos de Pedro Fernández en la comarca de Salas provienen principalmente de doña Mayor, quien actúa como auténtica jefe del linaje, a pesar de que la titularidad formal recae en el heredero varón. ${ }^{41}$ Mayor de Castañeda parece haber retenido la capacidad de disposición sobre el señorío de Salas hasta tan tarde como 1371, en que fundó el mayorazgo de Salas en favor de su hijo Pedro Fernández. ${ }^{42}$ Esto supone que la presencia de Pedro Fernández de Velasco al frente de Salas no provendría de su propia pujanza - probablemente escasa en el muchacho de 1352- sino de una posi-

38. En ocasiones el Becerro alude a este enlace para explicar derechos de los Haro, Álvarez Borge, "Nobleza y señoríos...", p. 75.

39. Pero no se puede descartar que Diego López de Haro fuese a un tiempo el esposo de doña Sancha y el padre de don Pedro, tal y como sugiere Álvarez Borge ("Nobleza y señorios..., p. 76). De ser así, los derechos que ejercen en 1352 don Pedro de Haro y doña Sancha, viuda de don Diego provendrían de una única herencia desdoblada.

40. González Crespo, Elevación de un linaje..., p. 48.

41. En este sentido, la entrada del Becerro para Castrillo de la Reina es explícita en señalar una presencia antigua de los Velasco en la zona, pero por vía de su madre, Mayor de Castañeda. LBB, XV, 5: "Este logar es behetria. $E$ an por deviseros don Nunno e don Pedro fio de don Diego; e este logar lo tien agora Pero Ferrnadez de Velasco e su avuelo e [sic] Diego Gomez e su madre e los de su linaje levaron siempre los derechos del dicho logar"

42. Cit. por Clavero, Mayorazgo..., p. 37. Doña Mayor se refiere a Salas en términos que indican claramente su titularidad: "...la mi casa de Salas con todo lo que a mi pertenece y pertenece a la dicha casa de Salas..." 
ción heredada de sus padres. Esto se percibe con especial claridad en el caso de Palacios de la Sierra, lugar solariego de los Velasco que se perfila en el texto del Becerro como producto de la herencia de Fernán Sánchez de Velasco. ${ }^{43}$ Aquí se registra el pago de una elevada martiniega en concepto de retenencia al castillo del lugar, como algo diferenciado del de Salas, a pesar de tratarse del mismo linaje. ${ }^{44}$ Teniendo en cuenta que Palacios pudo formar parte del grupo de lugares dependientes de Salas en el siglo XIII, sería una hipótesis verosímil que la presencia de los Velasco en la villa se remonta a Fernán Sánchez y que su paso de behetría a solariego pudo efectuarse en ese momento, cuando Salas estaba en manos de Diego López o de otros señores. Eso explicaría por qué no hay pagos a Salas: el pago al centro territorial se habría reconvertido en una prestación al castillo de los Velasco en la propia villa. La presencia patrimonial de los Velasco en el sector de Salas una generación atrás proporciona una interesante base previa para el acceso de Pedro Fernández al señorío de Salas.

¿Es posible esbozar una trayectoria evolutiva? Si utilizamos -con toda la prudencia que requiere el uso de una fuente apócrifa- la información proporcionada por el fuero falso de Salas, llama la atención un pasaje en el que se enumera las diez villas dependientes de Salas. Este pasaje -por contraste con otros del mismo fuero que reflejan claramente una situación de mediados del siglo XIV-describe una situación sumamente coherente, sin que nada permita sospechar diferencias en el estatuto señorial de los distintos lugares. ${ }^{45}$ Como indiqué más arriba, ésta podría ser la situación del siglo XIII, y correspondería a un estatuto generalizado de behetría, en que los vínculos descritos entre Salas y sus villas operarían de manera homogénea. En el panorama del momento, esta cohesión territorial es insólita y puede ser considerada un rasgo de arcaísmo, propio de las demarcaciones supralocales de los siglos X-XI ${ }^{46}$ En un segundo paso, algunos de esos lugares serían transformados en solariegos. Ese pudo ser el caso de Palacios de la Sierra - ¿quizás también Hornillos?-- bajo Fernán

43. LBB, XV, 71: "Este logar es solariego de donna Mayor, muger que fue de Ferrant Sanchez de Velasco, e de sus fijos e de donna Maria, muger de Digo Perez Sarmiento...".

44. LBB, XV, 71 (Palacios de la Sierra): "Dan cada anno a su sennor para la rretenençia del castillo del dicho logar mill maravedis". Sobre el castillo de Palacios, Escalona, Sociedad y territorio... y Estepa, "Organización territorial, poder regio y tributaciones militares...", p. 147.

45. De las diez aldeas de Salas enumeradas en el fuero, dos (Nava y Torneros) no figuran en el Becerro y uno (Pinilla de Cedrón) es de identificación problemática. Martínez Díez ( $P$ ueblos y alfoces..., p. 175) identifica Pinilla de Cedrón con el vecino Pinilla de los Moros, sobre el cauce del río Pedroso. Esta reducción me parece poco verosímil (Escalona, Sociedad y territorio...). No es posible ofrecer una alternativa clara entre los lugares de los alrededores, pero pienso que un candidato más probable sería Monasterio de la Sierra, cuyo topónimo es evidentemente tardío - LBB la denomina monasterio çerca de Salas- y podría haber reemplazado a Pinilla, topónimo que encajaría perfectamente con la topografía del lugar. El hecho de que Monasterio sea behetría en 1352 refuerza la impresión de que habría formado parte de las aldeas dependientes de Salas con anterioridad.

46. Escalona, "Unidades territoriales supralocales..." 
Sánchez de Velasco, antes o durante el período de señorío de Diego López de Haro en Salas. En tiempo de este último habrían pasado Castrovido y Terrazas a solariego de los Haro, y sólo desde 1350 se habría dado el señorío de Pedro Fernández sobre Salas y sus villas, así como fenómenos más o menos discordantes, como la vinculación de Villamiel.

Después de la guerra civil, Pedro Fernández de Velasco y sus sucesores terminan por consolidar Salas como centro de su señorío y capital comarcal. En 1371 tiene lugar la primera fundación del mayorazgo de los Velasco, a cargo de Mayor de Castañeda y a favor de su único hijo legítimo, Pedro Fernández de Velasco. En 1380 Pedro Fernández de Velasco establece dos mayorazgos para sus hijos, el primero radicado en el norte de Castilla y el segundo en Salas, aunque será el segundo hijo, llamado también Pedro, quien acabe heredando ambos mayorazgos. ${ }^{47}$ Dos documentos más constituyen el punto final del proceso. Por el primero el concejo de Salas solicita de Juan II que exima al lugar de las cargas que tiene como behetría y done la villa a Pedro Fernández de Velasco y a sus vecinos, vasallos solariegos del conde. ${ }^{48}$ Con este acto se rubrica de iure el largo proceso de acumulación de poder por parte de los Velasco en la región desde inicios del siglo XIV, transformando el variado panorama señorial de ese momento inicial en un casi absoluto predominio del linaje. Finalmente, en 1458 se funda el definitivo mayorazgo en el que se incluyen los lugares de Salas y la villa de Silos, adquirida en $1432 .{ }^{49}$

\section{La comarca de Juarros}

Juarros es un pequeño territorio situado al sudeste de Burgos, entre los alfoces medievales de Burgos, Lara y Ausín. El alfoz de Santa Cruz de Juarros se documenta por primera vez en $1032^{50}$, aunque hay razones para pensar que existía ya como distrito en el siglo $X .{ }^{51}$ Como ocurre con otras pequeñas demarcaciones de la Alta Edad Media, el proceso de su integración en las estructuras políticas del condado castellano supuso también el comienzo de su desarticulación interna, tanto debido al impulso de su propia evolución socioeconómica, como a la infiltración de elementos de poder externos, especialmente grandes monasterios y el propio poder condal. Este proceso fue en Juarros muy

47. Clavero, Mayorazgo..., p. 38.

48. FRIAS/1686, año 1439.

49. SALAZAR Y CASTRO, L., Pruebas de la Historia de la Casa de Lara, sacadas de los instrumentos de diversas Iglesias, Monasterios, de los Archivos de sus mismos descendientes, de diferentes pleytos que entre sí han seguido, y de los Escritores de mayor crédito y puntualidad. Madrid 1694, pp. 264 y ss.

50. BGC/71: "...monasterio santi Mikael in villa que vocitant Spinosa in alfoze de Sancta Cruce de Scuarros...".

51. Escalona, Sociedad y territorio...; Álvarez Borge, Monarquía feudal..., p. 78; Cfr. Martínez Díez, Pueblos y alfoces..., p. 79. 
intenso y dio lugar a una temprana e intensa fragmentación del viejo distrito. La acción de las entidades eclesiásticas, concretamente Cardeña, contribuye especialmente a esta desarticulación, a lo que hay que añadir la actuación -mas tardía, pero no menos contundente-de entidades como San Cristóbal de Ibeas, San Juan de Burgos o Las Huelgas.

El territorio de Juarros presenta una compleja mezcla de rasgos seculares con otros más recientes. En primer lugar, el desarrollo del señorío eclesiástico es muy temprano, especialmente en el área occidental del alfoz (Espinosa, Cueva, Cuzcurrita), la más afectada por los intereses de San Pedro de Cardeña. La documentación de Cardeña permite comprobar también la temprana presencia de poderes feudales laicos. Durante el siglo $X$ se documenta la presencia de personajes pertenecientes a linajes condales y magnaticios, así como otros de menor rango que podemos considerar propietarios de cierta relevancia local o comarcal. Este cuadro tiende a evolucionar en el siglo XI hacia un predominio casi exclusivo de los altos linajes nobiliarios, que parecen acaparar divisas $y$ heredades en el sector. Sin embargo, a largo plazo tiende a predominar el señorío eclesiástico, desplazando poco a poco a los linajes nobiliarios. Merece la pena comparar esta imagen con la del vecino alfoz de Ausín. En Ausín todavía en 1352 se documentan lugares de behetría como Hontoria de la Cantera o Cubillo del Campo, si bien predomina claramente el abadengo, incluso en la antigua cabecera territorial. ${ }^{52}$ En cambio, en Juarros no se registra behetría alguna, aunque sabemos que algunas localidades del antiguo alfoz - la propia Santa Cruz - tenían una organización próxima a la behetría a fines del siglo XII. ${ }^{53}$ En el Becerro de las Behetrías Juarros está representado por un total de 10 localidades de las cuales 3 son abadengo y 7 condominio de abadengo y solariego. ${ }^{54}$

52. El cuadro que el Becerro ofrece de los lugares del alfoz de Ausín es el siguiente:. LBB, XI, 61: Hontoria de la Cantera: Behetría (Señor singular: Pedro Ruiz Carrillo). LBB, XI, 60: Cubillo del Campo: Behetría (Señor singular: Pedro Ruiz Carrillo). LBB, XI, 62: Hontoria de Yuso: Behetría (Señor singular: doña Urraca, esposa de Pedro Ruiz Carrillo). LBB, XI, 113: Modúbar de San Cebrián: Realengo. LBB, XI, 105: Los Ausines: Abadengo del Obispo de Burgos y de Santa Apolonia de Los Ausines. LBB, Xl, 106: Revillarruz: Abadengo del Obispo de Burgos. LBB, XI, 107: Revilla de la Fuente: Abadengo de San Cristóbal de Ibeas y de Bujedo. LBB, XI, 108: Revilla del Campo: Abadengo de Las Huelgas y solariego de Gómez Carrillo. LBB, XI, 109: Quintanaseca: Abadengo de San Quirce y del monasterio de Ausín. LBB, XI, 110: Cubillo del César: Abadengo de Las Huelgas. LBB, XI, 111: Cuevas de San Clemente: Abadengo del Obispo de Burgos.

53. Álvarez Borge, Poder y relaciones sociales..., p. 276; Escalona, Sociedad y territorio...

54. El registro de Juarros en el Becerro es:. LBB, XI, 86: San Andrés de lbeas: Abadengo de San Cristóbal de lbeas . LBB, XI, 87: Mozoncillo de Juarros: solariego de Gómez Carrillo (5 solares) y abadengo de San Cristóbal de Ibeas (2 solares). LBB, XI, 88: Cueva de Juarros: solariego de Juan Estévanez (tiene el lugar) y Pedro Fernández de Velasco (2 solares) y abadengo de Renuncio (solares yermos). LBB, XI, 89: Cuzcurrita de Juarros: Abadengo de San Cristóbal de Ibeas. LBB, XI, 90: Espinosa de Juarros: solariego de Juan Estévanez (solares yermos) y abadengo de San Cristóbal de Ibeas. LBB, XI, 91: Santa Cruz de Juarros: solariego de Pedro Fernández de Velasco ( 5 solares) y abadengo de Las Huelgas ( 2 solares), San Cristóbal de lbeas (2 solares) 
Esta abundancia de condominio de abadengo y solariego, podría responder al desplazamiento de los diviseros por entidades religiosas y linajes nobiliarios desde dentro de una primitiva estructura de behetría, dando lugar a una alta fragmentación del poder señorial. De hecho, en un caso (Cueva de Juarros), a pesar de definir el lugar como solariego y de consignar que allí tenía Pedro Fernández de Velasco dos solares y el abad de Remizo un número no especificado de solares yermos, también se dice que Juan Estévanez "tenía el lugar", una expresión típica para aludir al señorío singular de las behetrías. De la misma manera, hay casos de extrema fragmentación, como Brieva de Juarros, junto a otros, como Salgüero de Juarros, donde un sólo señor acapara la mayor parte de los solares. En todo caso, el aspecto más llamativo es la elevada presencia del condominio de solariego y abadengo.

La mezcla de señores laicos y eclesiásticos en el nivel del señorio compartido puede ir pareja con la ausencia de referencias a un nivel de señorío singular, que en Juarros parece haberse difuminado tempranamente, en consonancia con el alto grado de desarticulacion de la cohesión del distrito como entidad supralocal..$^{55}$ Por to que se refiere al solariego, los linajes presentes son los Velasco, los Carrillo y Juan Estébanez de Castellanos, que parece poderse definir como un pequeño hidalgo local. ${ }^{56}$ Los Carrillo sólo aparecen en MozonciIlo de Juarros ${ }^{57}$-aunque con una participación notable en el lugar- y Juan Estébanez en Ibeas, Espinosa y Cueva de Juarros. En cambio, el linaje más representado son los Velasco, de los que el único miembro registrado es el cabeza del linaje, Pedro Fernández. Dado que el Velasco comparte señorío con diferentes entidades eclesiásticas, pero con ningún otro señor laico excepto Juan Estévanez, es difícil determinar cuándo se pudo producir su entrada en el panorama señorial de la comarca. Una hipótesis verosímil sería pensar que lo hizo a través del entronque con los Carrillo. Pero Ruiz Carrillo y su esposa aparecen como señores de las vecinas behetrías del antiguo alfoz de Ausín, y los herederos de Gómez Carrillo tenían la mayor parte Mozoncillo de Juarros, la

y Bujedo (1 solar). LBB, XI, 92: Brieva de Juarros: solariego de Pedro Fernández de Velasco (1 solar) y abadengo Foncea ( 2 solares), Las Huelgas (1 solar) y Villalbura (1 solar). . LBB, XI, 93 : Salgüero de Juarros: Solariego de Pedro Fernández de Velasco ( 7 solares) y abadengo de San Cristóbal de Ibeas (1 solar). LBB, XI, 95: Ibeas de Juarros: solariego de Juan Estévanez (3 solares poblados y otros yermos) y abadengo de San Cristóbal de lbeas (solares yermos). LBB, XI, 96: San Adrián de Juarros: Abadengo de San Juan de Burgos (la mitad) y de San Cristóbal de ibeas (la otra mitad).

55. Escalona, Sociedad y territorio...

56. Sobre este personaje, ver MOXÓ, S., "Juan Estébanez de Castellanos. Elevación y caída de un consejero regio en la Castilla del siglo XIV", Homenaje a Fray Justo Pérez de Urbel, Santo Domingo de Silos, 1976, t. I, pp. 407-421 y Álvarez Borge, "Nobleza y señoríos...", pp. 90-91, y Martínez Díez, LBB, I, p. 96.

57. Gómez Carrillo había muerto ya. En 1352 sus derechos estaban indivisos entre sus herederos, los "hijos de Gomez Carrillo"del Becerro. Álvarez Borge, "Nobleza y señoríos..." pp. 75 y 105. 
única villa de Juarros donde se registra presencia señorial de los Carrillo. Dado que ambos distritos parecen haber seguido una trayectoria paralela en cuanto a su señorializáción, no es absurdo pensar que donde aparecen los Velasco en juarros hubo antes una presencia señorial de los Carrillo, como también sucede hasta cierto punto en Valdelaguna.

En el ámbito del antiguo alfoz de Juarros no se registran prestaciones de carácter territorial como pagos al Castillo de Burgos, que sí se dan, en cambio, en el alfoz de Ausín. Allí son cinco las villas que tributan prestaciones al Castillo de Burgos, de las que tres son las únicas behetrías del viejo alfoz y dos son lugares cuyo dominio señorial corresponde íntegramente a la Catedral de Burgos. ${ }^{58}$ En todos los casos la prestación se registra como martiniega. ${ }^{59}$ Las analogías con el caso de Salas son evidentes, en especial en lo referente a la relación entre este tipo de pagos y el estatuto de behetría. En cambio, el contraste es notable con Juarros, donde no hay pagos a ningún castillo, la cohesión territorial está muy desdibujada, no hay behetrías y la Catedral no ejerce el dominio señorial de manera exclusiva o compartida en villa alguna.

La imagen sumamente desarticulada del territorio del Juarros ofrece un interesante contrapunto al caso de Salas de los Infantes. Para terminar, veamos el ejemplo intermedio del sector de Valdelaguna.

\section{El alfoz de Barbadillo y el sector de Valdelaguna}

El alfoz de Barbadillo es un pequeño territorio situado al este de Lara. Su trayectoria en los siglos X y XI es bastante confusa, debido a la carencia de datos hasta fechas relativamente tardías. Se documenta por primera vez en el diplo-

58. En Cuevas de San Clemente (abadengo del Obispo de Burgos) se paga una martiniega de 86 maravedíes, repartida en 46 para el Castillo de Burgos, 22 para el Adelantado y 18 para el Obispo; en Revillarruz (abadengo del Obispo de Burgos) se paga una martiniega de 76 maravedies, repartida en 34 para el Castillo de Burgos, 18 para el Obispo, 18 para el Adelantado y 6 para el cogedor por carta de pago); en Cubillo del Campo (behetría) se pagan 157 maravedíes, de los cuales 150 son para el Castillo de Burgos y 7 para el Adelantado); en Hontoria de la Cantera (behetría) se pagan 113 maravedíes, de los cuales 103 son para el Castillo, 4 para el adelantado y 6 para el cogedor por carta de pago; en Hontoria de Yuso (behetría) se paga una martiniega de 36 maravedíes al Castillo de Burgos y 16 dineros al Adelantado.

59. Es interesante el caso de la antigua cabecera del alfoz, Los Ausines. Dicho lugar en 1352 es abadengo del obispo de Burgos y del monasterio de Santa Apolonia de Los Ausines. En el Becerro se especifica que no pagan martiniega por privilegio del abad y el obispo. En otras otras aldeas próximas dependientes del obispado (Revillarruz, Cuevas de San Clemente) se paga martiniega al Castillo de Burgos, lo que indica que el privilegio en cuestión no afecta a todas las posesiones episcopales, ni siquiera las muy cercanas. En mi opinión, debería tenerse en cuenta como hipótesis que esta exención de martiniega puede proceder del acuerdo suscrito en el año 972 entre el concejo de Ausín y el conde García Fernández, por el cual los primeros entregaban la Dehesa de la Loma a cambio de la exención "de illo labore de illos castellos" (BGC/3), prestación que podría haberse canalizado tardíamente hacia el pago de martiniega al Castillo de Burgos. 
ma fundacional del Infantado de Covarrubias $(\mathrm{ClC} / 7,978)$ y desde mediados del siglo XI podría haber sido absorbido por el alfoz de Lara. ${ }^{60}$ Se trata de un fenómeno presente en toda la zona serrana, por el cual los alfoces de menor tamaño tienden desarticularse y perder su significación como unidades territoriales, como ocurre con los de Tabladillo, Huerta o, liquidados a lo largo del siglo XII para integrarse en el dominio de la abadía de Silos en 1125, 1137 y 1152 respectivamente. ${ }^{61}$

Se ha discutido cuál pudo ser el centro de esta demarcación. Martínez Díez ha propuesto Barbadillo de Herreros, ${ }^{62}$ y Álvarez Borge parece inclinarse por Barbadillo del Pez. ${ }^{63}$ Por mi parte, pienso que Barbadillo pudo ser un distrito un tanto artificial, compuesto por dos sectores bien diferenciados: el valle alto del

60. La idea de la incorporación de Barbadillo a Lara en los años 60 del siglo XI se basa principalmente en dos documentos. Por el primero de ellos (SPA/62, año 1062), Fernando I entrega a Arlanza el diezmo de los palacios regios situados en los alfoces de Tabladillo, Barbadillo, Huerta, Tabladilio y San Esteban. Esta donación fue parcialmente reiterada por Sancho II en 1069 (SPA/73). Al margen de los problemas de transmisión que presentan estos textos, debe hacerse notar que la cesión sólo establece la participación del monasterio en las rentas gestionadas por dichos "palacios", lo cual, lejos de suponer la desaparición de los mismos parece confirmar más bien su importancia. Es claro que a largo plazo la monarquía parece tender a desprenderse de estos centros de gestión señorial (Álvarez Borge, Monarquía feudal..., pp. 29 y ss.), pero no puede inferirse de ello que se diese una concentración de distritos como tal. En el caso del alfoz de Lara dicha concentración parece haberse producido, pero de una manera más laxa y sin implicar una centralización administrativa (no parece, por ejemplo, que el palatium de Lara absorbiese la gestión de los distritos circundantes). Si hay que apuntar a un mecanismo clave en el proceso, éste debe ser la tendencia de los señores de Lara a concentrar en sus manos el señorío sobre los espacios contiguos entre mediados del siglo XI y mediados del XII (Escalona, Sociedad y territorio...). Creo que es en este sentido como hay que entender la creación de un amplio territorio designado (en realidad de manera impropia) como alfoz de Lara. Así, se localiza en 1062 Vizcaínos, Huerta de Abajo, Barbadillo de Herreros y Riocavado en el alfoz de Lara (SPA/63) y en 1156 se habla del "territorio de Lara" para ubicar Revilla de la Fuente (SPA/113).

61. Escalona, Sociedad y territorio...

62. Dicho autor considera que sólo Valdelaguna formó parte del alfoz de Barbadillo, por lo que el centro territorial más verosímil sería Barbadillo de Herreros. Si se acepta que el distrito englobaba también Barbadillo del Mercado, entonces éste último resulta ser el más probable.

63. Álvarez Borge, Monarquía feudal..., pp. 59-60. Barbadillo del Pez había sido donado al Infantado de Covarrubias por García Fernández en 978 ( $\mathrm{ClC} / 7)$, circunstancia que para Álvarez Borge habría propiciado la desarticulación del alfoz y su absorción por Lara. Sin embargo, esta opción me parece menos verosímil por dos razones: a) porque sería extraña la cesión a Covarrubias de la cabecera del alfoz, sin implicaciones más amplias para el distrito, donde Covarrubias no recibe nada más. El caso de Barbadillo del Pez es paralelo a la solitaria cesión de la aldea de Talamanquilla en el alfoz de Tabladillo. He interpretado que en ambos casos el disfrute de señorío sobre un lugar del alfoz habilitaría a Covarrubias para participar en los aprovechamientos silvopastoriles de todo el distrito (Escalona, 'Jerarquización social y organización del espacio..."); b) porque, en todo caso en 1062 los monarcas retenían allí un palatium en estado plenamente operativo, cuyo diezmo pudieron donar a Arlanza sin aparentes interferencias con el Infantado. 
río Pedroso - comarca que desde la Edad Media se conoce con el nombre de Valdelaguna- y el valle bajo del mismo río, desde Vizcaínos a Barbadillo del Mercado, ${ }^{64}$ que sería su centro administrativo. Esta unidad habría operado en los siglos $\mathrm{X}$ y XI para desgajarse finalmente en dos bloques, el de Barbadillo del Mercado (Barbadillo propiamente dicho) y el de Valdelaguna, con niveles diferentes de integración en el alfoz de Lara. ${ }^{65}$ En el Becerro de las Behetrías la parte meridional de este distrito se muestra sumamente desdibujada -de hecho, el sector de Barbadillo del Mercado no figura en el Becerro, como se ha dichopero en cambio Valdelaguna acusa una fuerte personalidad que ha perdurado hasta nuestros dias. ${ }^{66} \mathrm{Me}$ centraré, pues, en el análisis de Valdelaguna.

Dentro de este ámbito, y al igual que ocurre en el caso de Juarros, el Becero no registra ninguna behetría a excepción de Neila, cuya inclusión en el viejo alfoz me parece descartable. ${ }^{67}$ Excluida ésta, quedan 11 localidades, de las cuales 2 son abadengos y otras 9 solariegos. No existen condominios. De las dos aldeas de abadengo, Barbadillo del Pez se documenta desde 978, en que es entregada a Covarrubias, ${ }^{68}$ de cuya honor seguía formando parte en 1352 . EI otro lugar de abadengo es Villa Sarracín, que pasó a poder de Arlanza a través de un intercambio efectuado con Nuño Pérez de Lara en 1174. Este texto es de una importancia primordial para comprender la evolución del sector: adopta la forma de una permuta en que el rey da a Arlanza Villa Sarracín, a cambio de Huérmeces, que será dada al conde de Nuño Pérez de Lara "in cambio". ${ }^{69}$ Otro

64. La delimitación de Martínez Díez (Pueblos y alfoces..., pp. 195-196) se basa en las demarcaciones eclesiásticas de la Plena y Baja Edad Media, concretamente en las divisiones entre los arciprestazgos de Mansilla y Lara. No cabe duda de que los arciprestazgos tienden con frecuencia a establecerse sobre unidades territoriales preexistentes, sin embargo, en el caso de Barbadillo, pienso que el arciprestazgo de Mansilla sólo incorpora una parte del antiguo alfoz, quedando el resto en el de Lara.

65. Escalona, Sociedad y territorio... Todavía en el siglo XIII, la donación de Alfonso X al Concejo de Burgos, a pesar de cederlas en bloque, trata como unidades diferentes a Lara y a Barbadillo del Mercado, en probable recuerdo de su diferente personalidad administrativa en el pasado (CDCB/30, 1255). Por su parte Valdelaguna todavía tenía en 1285 una personalidad diferenciada de Lara y de Barbadillo como demarcación para la percepción de rentas regias (CDCB/144).

66. La comarca ha mantenido a través de los siglos una cohesión socioenómica muy notable, de ahí que fuese una de las áreas de la provincia de Burgos en las que Joaquín Costa encontró mayor número de datos para su obra sobre el colectivismo agrario (COSTA, J., Colectivismo agrario en España. Obras de Joaquín Costa, 7 y 8. Madrid, 1983). Ver también GIMÉNEZ ROMERO, C., Valdelaguna y Coatepec. Permanencia y funcionalidad del régimen comunal agrario en España y México, Madrid, 1991.

67. Escalona, Sociedad y territorio... Cfr. Martínez Díez, Pueblos y alfoces..., p. 195.

68. ClC/7: "De Barbatello: Barbatello de Albaro Telliz".

69. SPA/121 (1174): "...dono et concedo monasterio Sancti Petri de Arlanza (...) villam don Sarrazin in cambio pro alia villa vestra que a vulgo Guermezes noncupatur, quam vos predicte ville cambiacione comiti Nunnioni et dompne Terese cometisse mulieri sue in cambio datis et concidatis...". 
documento de 1193 establece la donación de las heredades del rey en Villa Sarracín, a la par que confirma su transmisión por permuta. ${ }^{70}$ Por lo tanto, el rey tiene la iniciativa de entregar Villa Sarracín a Arlanza, pero ello lleva aparejada una indemnización a Nuño Pérez de Lara. El caso es semejante al de la villa de Cabezón, que fue donada a Arlanza por Alfonso VIII en 1172, con la aceptación del conde Pedro Manrique de Lara, que tenía la villa "in honore". ${ }^{71}$ En ambos casos parece haber un poder señorial sobre el conjunto de la villa que resulta afectado por la cesión regia. Estos casos deben ser comparados con el de Pinilla de los Barruecos, que fue entregada por Alfonso VII a Santo Domingo de Silos en 1171 (SDS/65), pero cincuenta años después aún había caballeros con heredades en la villa, que reclamaban derechos a un dominio señorial que el monasterio pretendía tener en exclusiva. ${ }^{72}$ En general, da la impresión de que estas concesiones pueden a veces estar actuando sobre lugares de behetría o con formas señoriales próximas a la behetría en tanto en cuanto hay dos niveles de ejercicio del señorío presentes en ellas. El caso de Villa Sarracín sugiere que Nuño Pérez de Lara podía tener derechos señoriales sobre el lugar-de ahí la entrega de Huérmeces en contrapartida- pero sometido a la superioridad del poder regio, lo cual es también característico del señorío singular de behetría. ${ }^{73}$ En cualquier caso, se demuestra que la presencia del abadengo en el territorio de Barbadillo se remonta a fechas muy anteriores a la redacción del Becerro.

Por lo que se refiere al señorío solariego, la nota más destacable es su extrema fragmentación. En siete de las nueve villas solariegas se registran cuatro o más señores, siempre laicos, puesto que no hay condominios de abadengo y solariego. ${ }^{74}$ Dentro de esa fragmentación, el cuadro es sumamente coherente,

70. SPA/128: "Preterea pretaxato monasterio dono regaliter et cencedo quidquid habeo in Turre de domna Imblo et in Cantarellos, et in Villaverde et in Sancto Johane de Cella et in Xaramello mediano et in Caniçera et in Villa Sarraçín, quam predicto monasterio dedi in concambio pro illa villa que dicitur Guermeçes...".

71. SPA/119: "Comes Petrus prescriptam villam in honore tenens et hoc donativum volens, confirmat et laudat". Sobre este texto, JULAR PÉREZ-ALFARO, C., 'Aproximación a la terminología territorial de la monarquía feudal. El "honor" en la documentación regia de León y de Castilla en la segunda mitad del siglo XII', III Jornadas Burgalesas de Historia. Burgos en la Plena Edad Media. Burgos, 1994, pp. 609-621. Sobre el significado de esta transacción en la estructura señorial de la zona, Escalona, "Unidades territoriales supralocales..."

72. Ver la composición acordada en 1230 (SDS/113) entre Silos y los herederos del castillo de Pinilla (con Pedro Martínez de Zayas a la cabeza), en que se respeta la capacidad de los caballeros para tener heredades en la villa, pero se acuerda el señorío de Silos sobre ella, así como, significativamente, destruir el castillo. Escalona, Sociedad y territorio...

73. Para más precisiones, Escalona, "Unidades territoriales supralocales..."

74. El cuadro ofrecido por el Becerro para Valdelaguna es el siguiente:. LBB, XII, 36: Barbadillo del Pez: Abadengo de Covarrubias. LBB, XV, 35: Villa Sarracín: Abadengo de Arlanza. LBB, XV, 40: Vallegimeno: Solariego de Pedro Fernández de Velasco y Diego Pérez Sarmiento por doña María, su mujer. LBB, XV, 42: Bezares: Solariego de Pedro Fernández de Velasco. LBB, XV, 43: Tolbaños de Arriba: Solariego de Pedro Fernández de Velasco, doña María (su hermana), Juan Sánchez de Velasco y los hijos de Juan Martínez de Leyva. LBB, XV, 44: Huerta de 
sin embargo. Se trata de solariegos compartidos por un grupo de señores casi constante; en algún lugar puede faltar alguno de ellos, pero no hay intromisiones de otros señores. Los linajes representados son los hijos de Gómez Carrillo, los hijos de Juan Martínez de Leiva ${ }^{75}$ y los Velasco (Juan Sánchez de Velasco ${ }^{76}$, Pedro Fernández de Velasco, o bien su hermana, doña María ${ }^{77}$ ) con una clara tendencia al predominio de los últimos. Esta reiteración de los mismos señores solariegos en casi todos los lugares se asemeja más bien a los diviseros de las behetrías. ¿Cabría preguntarse si los lugares de Valdelaguna podrían tener una situación próxima a la behetría, pero haber sido registrados en el Becerro como solariegos? Las prestaciones de carácter territorial constituyen un argumento muy interesante en este sentido.

De las once aldeas del sector, en un total de seis se consignan pagos de prestaciones de carácter territorial. De los abadengos, Villa Sarracín -lugar de Arlanza - no efectúa pagos de este tipo pero Barbadillo del Pez paga martiniega al Castillo de Burgos; aunque no concuerde con el resto del territorio, se trata de una situación lógica, puesto que pertenece a la honor de Covarrubias y todas sus aldeas participan de ese rasgo. En cambio, de los solariegos, cinco lugares realizan pagos al castillo de Lara en concepto de retenencia, y un sexto probablemente los había realizado hasta poco antes de $1352 .{ }^{78}$

Abajo: Solariego de Pedro Fernández de Velasco, doña María (su hermana), Juan Sánchez de Velasco, los hijos de Gómez Carrillo y los hijos de Juan Martínez de Leyva. LBB, XV, 45: Tolbaños de Abajo: Solariego de Pedro Fernández de Velasco, doña María (su hermana), Juan Sánchez de Velasco, los hijos de Gómez Carrillo y los hijos de Juan Martínez de Leyva. LBB, XV, 46: Huerta de Arriba: Solariego de Pedro Fernández de Velasco, doña María (su hermana), los hijos de Gómez Carrillo y los hijos de Juan Martínez de Leyva. LBB, XV, 47: Riocavado: Solariego de Pedro Fernández de Velasco, doña María (su hermana), Juan Sánchez de Velasco, los hijos de Gómez Carrillo y los hijos de Juan Martínez de Leyva. LBB, XV, 48: Quintanilla de UrriIla: Solariego de Pedro Fernández de Velasco, doña María (su hermana), Juan Sánchez de Velasco y los hijos de Gómez Carrillo. LBB, XV, 49: Barbadillo de Herreros: Solariego de Pedro Fernández de Velasco, doña María (su hermana), Juan Sánchez de Velasco, los hijos de Gómez Carrillo y los hijos de Juan Martínez de Leyva.

75. Tanto Gómez Carrillo como Juan Martínez de Leyva habían fallecido ya y sus derechos se registran indivisos entre sus hijos (Álvarez Borge, "Nobleza y señoríos...", pp. 72-75).

76. Sobre este personaje, Álvarez Borge, "Nobleza y señoríos...", p. 88.

77. Esta dama casó con Diego Pérez Sarmiento, que a veces figura como titular del señorío, pero especificándose que lo tiene por su esposa. Sobre las relaciones entre esta rama de la familia y el conjunto del linaje, ver los comentarios de C. Jular ("Familia y clientela en dominios de behetría..." y "Nobleza y relaciones clientelares. El caso de los Velasco", en Estepa y Jular (Coords.): I Jornadas sobre el Feudalismo Castellano, en preparación). Menos frecuentemente se indica que la titular es la madre de los dos primeros, doña doña Mayor de Castañeda, esposa de Fernán Sánchez de Velasco y sus hijos, mención que conserva la memoria de la introducción del linaje en la comarca. Igualmente aparece como señor solariego Juan Sánchez de Velasco, pariente colateral de los anteriores (Álvarez Borge, "Nobleza y señoríos...", p. 88).

78. LBB, XV, 44 (Huerta de Abajo): "Da mas el que es casado al castiello de Lara pora la rretenençia un carnero". LBB, XV, 45 (Tolbaños de Abajo): "Dan al castiello de Lara cada casado pora la rretenençia un carnero". LBB, XV, 46 (Huerta de Arriba): "Dan al castiello de Lara 
La retenencia, que en la práctica puede confundirse con martiniegas asignadas a castillos, ${ }^{79}$ debe ser puesta en relación con la existencia de prestaciones militares a la villa cabecera por parte de las aldeas de los antiguos alfoces. ${ }^{80}$ En el caso de Valdelaguna los pagos al castillo de Lara tienen su lógica en la absorción del sector por el alfoz de Lara en torno a los años 60 del siglo XI. Se trata de un rasgo de arcaísmo que en 1352 estaba en proceso de desaparición, ya que Lara estaba en plena decadencia como centro jerárquico comarcal ${ }^{81}$ y no todos los lugares pagaban esas rentas. Los dos abadengos no lo hacían, y tampoco los solariegos de Bezares, Vallegimeno y Tolbaños de Yuso. No puede ser una casualidad que Vallegimeno y Bezares sean los dos lugares donde la presencia señorial de los Velasco es más intensa: es claro que coincide la ausencia de pagos a Lara con la presencia exclusiva del linaje Velasco. Si recordamos que en Quintanilla de Hurrilla -donde los Velasco constituyen tres de los cuatro poderes señoriales del lugar- había habido pagos al castillo de Lara, pero ya no los había, parece una hipótesis razonable que la eliminación de estos pagos está en relación con los intereses señoriales de los Velasco.

En el sector de Valdealguna, las aldeas con un señorío solariego más fragmentado, próximo al de los diviseros de behetrías, son las que mantienen los arcaicos pagos de carácter territorial al castillo de Lara, que son caraterísticos de las behetrías, como se vio en el caso de Salas. Esto parece confirmar la hipótesis de que, o bien se trata de antiguas behetrías reconvertidas en solariego, o bien son verdaderas behetrías, pero el Becerro evita registrarlas como tales. ¿Sería posible que los lugares de Valdelaguna fueran hasta poco antes de 1352 un bloque de behetrías, cuyo señor singular fuese un Lara -de ahí la pervivencia de las retenencias al castillo de Lara- y que los Velasco, al introducirse en el sector, intentasen reconducir la situación en su favor?

Un dato a favor de esta hipótesis es que no es el de los Lara el único poder señorial omitido en el Becerro al registrar Valdelaguna. A lo largo de los siglos XI y XII diversas entidades eclesiásticas, como Arlanza, San Millán, Cardeña o el

pora la rretenençia veynte e quatro maravedis". LBB, XV, 47 (Riocavado): "Dan al castiello de Lara para rretenençia del castiello quarenta e ocho maravedis". LBB, XV, 48 (Quintanilla HurriIla): "Dan al castillo de Lara pora rretenençia ninguna cosa". LBB, XV, 49: (Barbadillo de Herreros): "Dan al castiello de Lara cada anno pór fonsadera e rretenençia $L X V I m^{\prime \prime}$

79. Estepa, "Organización territorial, poder regio...", pp. 139-140.

80. Escalona, "Unidades territoriales supralocales...". El carácter de prestación militar es claro en Barbadillo de Herreros, donde se registra el pago de "fonsadera e retenençia" (LBB, $X V$, 49). Estepa, "Organización territorial, poder regio...", p. 140.

81. El pago se efectúa al castillo de Lara, no al Concejo. Desde 1255 el concejo de Burgos era señor de Lara, pero no de su castillo. Sólo en 1299 Fernando IV cedió el castillo al concejo de Burgos "porque los nuestros enemigos avien cobrado la penna do el castillo de Lara esta e lo labravan de nuevo e lo basteçian pora nuestro deserviçio e lo cobraron ellos pora el nuestro serviçio" (CDCB/158). A la altura de 1352 es evidente que los pagos al castillo de Lara redundaban a la larga en beneficio de Burgos, pero es interesante que se registren en relación con el viejo centro territorial. 
Obispado de Burgos, habían ido acumulando derechos en el sector. El caso de Arlanza es elocuente. ${ }^{82}$ El Libro de Cuentas de 1338 registra que el monasterio tenía una buena cantidad de propiedades en el sector, que, sin embargo estaban en su mayor parte arrendadas, a veces a miebros de los linajes que el Becerro muestra como señores solariegos. ${ }^{83} \mathrm{El}$ Becerro no hace mención alguna de esta situación y podría pensarse que Arlanza las había perdido antes de 1352. Sin embargo, en la conocida querella de las entidades monásticas de la zona contra Pedro Fernández de Velasco en 1380 se revela que Arlanza tenía solares en Vallegimeno y Riocavado, pero que el señor de Salas los tenía en encomienda forzosa. ${ }^{84}$ Ante este cuadro parece ajustado concluir que la forma en que el Becerro registra Valdelaguna acusa cierta parcialidad hacia los Velasco, al omitir los derechos eclesiásticos que años después están siendo tomados por fuerza.

Recapitulando, creo que se puede proponer el siguiente esquema evolutivo para el sector de Valdelaguna: En la Alta Edad Media habría constituído una demarcación, el alfoz de Barbadillo, junto con el curso bajo del río Pedro hasta Barbadillo del Mercado. La primera escisión habría sido el paso de la villa de Barbadillo del Pez al abadengo de Covarrubias en 978. Hacia 1060, el alfoz de Barbadillo se habría integrado en el de Lara, con lo que el señor de Lara lo sería también de los lugares de Valdelaguna. En el siglo XII esta fórmula señorial habría tendido a cristializar en la modalidad de behetría, por lo que el poder regio habría mantenido un alto poder de intervención sobre el nivel señorial superior. Esto explica que la cesión de Villa Sarracín a Arlanza fuese acompañada de una indeminización a Nuño Pérez de Lara, que probablemente sería señor en las behetrías del sector. Pienso que la tendencia dominante en Valdelaguna en la Plena Edad Media habría consistido en lugares de behetría que realizaban pagos al castillo de Lara por estar incluídos en su alfoz y que probablemente tenían a un Lara ${ }^{85}$ por señor singular, como las behetrías de Salas

82. Escalona, Sociedad y territorio...

83. Así, en el caso del monasterio de San Cristóbal de Vallegimeno se dice: "S. Cristoval de Valdelaguna lo tién $D^{a}$ Aldonça, muger que fue de Fernán Sánchez de Velasco, por su vida e renta 18 almudes de pan. Dio por ello mil maravedis. Diogelo el abad D. Ferrrando e ha XV años que lo tien" y en el de Villa Sarracín, "Villasarracin... tien $D^{a}$ Hurraca, mujer que fué de Gómez Carriello, por 20 años por 5.000 mạravedís que dió Gómez Cariello por ello e son passados 12 años e alo de tener ocho...". Otros arrendamientos tienen por beneficiarios a personajes de procedencia diferente, como Fernán Pérez de Aceves en Vallegimeno ("EI heredamiento de Villaximeno tién Fernán Pérez de Hazeves por XII años e son passados lo VIII. Renta $X$ almudes de pan cada año. Diógelo el abad D. Juan; no dió nada por ello") o Juan García de Mesa en Riocavado ("... los solares de Riocavado tién Joan García de Mesa por su vida y empeñárongelo el abat Don Joan y el convento. Ha nueve años que lo tién y renta seis cargas de pan...")

84. La referencia textual concreta a los intereses de Arlanza: Serrano, Cartulario de San Pedro de Arlanza..., pp. XIII-XIV. Álvarez Borge, Poder y relaciones sociales..., pp. 224 y ss.

85. Las asignaciones de señoríos entre ramas de la familia explicarían que en 1174 Nuño Pérez fuese señor de Villa Sarracín cuando en ese mismo período era Pedro Manrique el tenente de Lara. Álvarez Borge, Monarquía feudal..., pp. 210-211; Escalona, Sociedad y territorio... 
tenían en 1352 por señor al Velasco. La incompleta imagen del Libro de Cuentas de 1338 sugiere que hacia el primer tercio del siglo XIV la presencia señorial de Carrillos y Velascos ya era sustancial. ${ }^{86}$ El crecimiento de los Velasco en la zona redundó en la desarticulación de su cohesión supralocal: se tiende a negar la condición de behetría en favor del solariego y se suprimen los pagos a Lara en los lugares en que los Velasco alcanzan una posición de fuerza. Este rasgo de arcaísmo sería liquidado definitivamente en los años siguientes, al compás de la consolidación del poder de los Velasco en la región.

\section{Conclusiones}

Podemos aceptar, como viene siendo general, que la forma de señorío más extendida en la Plena Edad Media era la behetría, no sólo porque hay abundantes ejemplos de behetrías en el sector, sino también porque la intensa fragmentación del solariego -o condominio de solariego y abadengo- en muchas aldeas permite pensar en una situación previa de behetría -0 próxima a la behetría- convertida en solariego sobre la base de los diviseros de la aldea. Esta fragmentación señorial puede ser considerada un rasgo de arcaísmo, que se da en función de la existencia previa de una modalidad señorial distinta y que, de hecho, los señores trataron de superar por medio de procesos de acumulación y concentración de los que los Velasco proporcionan uno de los mejores ejemplos. La articulación supralocal de las behetrías en el sector de Salas es probablemente el rasgo más arcaico que podemos detectar, ya que remite a unidades territoriales altomedievales. En Valdelaguna se puede deducir que existió una articulación análoga, ya muy degradada en 1352, como también la pudo haber en Ausín. En cambio en Juarros parece que, si existió, su deterioro fue mucho más intenso y precoz, sin apenas huellas en el registro del Becerro.

El abadengo, como modalidad señorial muestra su presencia en el sector desde etapas muy antiguas, pero parece formarse por dos vías distintas: en primer lugar, la concesión de señorío sobre villas íntegras por parte del poder condal/regio. Esto remite al poder señorial ejercido por los condes y reyes sobre la totalidad del territorio. Significativamente en el siglo $X$ parece tratarse de donaciones no conflictivas, como la de Barbadillo del Pez a Covarrubias en 978, pero en el siglo XII el desarrollo de la modalidad señorial de behetría da lugar a casos en los que se ve que la donación regia se da sobre lugares en los que hay un señor singular (casos de Villa Sarracín o Cabezón) y diviseros (caso de Pinilla de los Barruecos). En segundo lugar, está la infiltración fragmentaria de

86. Recuérdese que Sancho Sánchez de Velasco (abuelo de Pedro Fernández) había casado con Sancha García Carrillo, lo que explicaria la presencia conjunta de éstos y los Velasco en áreas como Valdelaguna y Juarros, entre otras. La segunda vía de ampliación patrimonial vendría por el casamiento de Fernán Sánchez de Velasco con Mayor de Castañeda, hija de Diego Gómez de Castañeda y Juana Fernández de Guzmán. González Crespo, "Los Velasco en el horizonte...", pp. 338. 
poderes eclesiásticos en las aldeas a través de la adquisición de propiedades y derechos, por diferentes vías. Esta infiltración parcial parece operar en un universo de relaciones próximo al de los herederos y diviseros, y tiende a dar lugar a dos situaciones diferentes: o bien el desarrollo de la propiedad nobiliaria laica tiende a excluir al abadengo del dominio señorial y limitar su presencia a la propiedad dominical, o bien el desarrollo del abadengo bloquea la formalización de la villa como behetría o como solariego íntegro, dando lugar a los condominios que abundan en Juarros, por ejemplo. En Juarros, la presencia del señorío eclesiástico es muy antigua y probablemente es la clave que explica la temprana desarticulación del sector y el alto nivel de fragmentación señorial.

La gran novedad estriba en la conversión de behetrías en solariegos, proceso que sin duda se venía dando desde antiguo, incluso bloqueando la formalización de lugares de behetría como tales, pero que parece acelerarse desde mediados del siglo XIII. En el área estudiada se puede demostrar que muchas de esas reconversiones no se remontan más allá de dos generaciones y que algunas -casos de Valdelaguna- estaban en pleno proceso en 1352. El estudio del área de Salas revela que las sucesivas etapas de disfrute del señorío de behetría sobre la zona pudieron también dar lugar a la conversión de lugares concretos, como los solariegos de los Haro en la zona. En último término, fueron los propios Velasco los que primero utilizaron el señorío singular de behetría para cimentar su presencia en Salas -donde sólo eran diviseros en dos lugares- y luego forzaron la conversión al solariego.

Una hipotética reconstrucción del proceso de extensión del poder señorial de los Velasco en la zona podría ser ésta:

- De comienzos del XIV puede ser la adquisición de los derechos en Juarros, donde aparecen vinculados a los Carrillo (matrimonio de Sancho Sánchez de Velasco con Sancha García Carrillo).

- De una generación después pueden ser los solariegos de Hornillos y Palacios (matrimonio de Fernán Sánchez de Velasco con Mayor de Castañeda, descendiente de Guzmanes).

- De fecha algo anterior a 1350 serían los solariegos de Barbadillo. Aquí también se puede hablar de una presencia antigua de los Velasco, quizá vinculada a los Carrillo, pero dentro de una modalidad de behetría. La conversión al solariego -si se dió relamente- debe de ser poco anterior a 1350 , puesto que las antiguas behetrías conservan los pagos a Lara, pero aquéllas donde los Velasco son los únicos señores los suprimen. Da la impresión de que podría ser un proceso posterior a los antes citados, pero anterior al acceso de Pedro Fernández de Velasco a la jefatura de la Casa de Salas.

- Finalmente, tenemos la adquisición del señorío de Salas, en torno a 1350 y el ejercicio de poderes señoriales sobre aldeas de los alrededores en función de su dependencia territorial respecto de esta villa. Quizá la vincu- 
lación de Villamiel a Salas a través de pagos proceda de este momento, puesto que anteriormente el señor de Salas era. Diego López de Haro, que no figura como señor en Villamiel.

Para terminar hay que decir que el análisis de la información del Becerro de las Behetrías permite definir un jalón muy importante en el proceso de desplazamiento de la jerarquía territorial de la comarca serrana de Lara a Salas. Se puede considerar que la presencia de rentas de carácter territorial refleja, aunque de forma difusa la existencia de antiguas jerarquías territoriales. A la altura del siglo XIV, algunas de ellas habían perdido casi todo su significado, pero quedan restos que pueden ser valorados como arcaísmos y permiten un análisis retrospectivo sobre las realidades de la Alta y Plena Edad Media. En el caso de abadengos y solariegos, ya sean antiguos o recientemente constituidos a partir de behetrías, se tiende a suprimir estas cargas de tipo territorial, lo que indica que su naturaleza permanece más bien ligada a las behetrías y a la organización en alfoces característica de la Alta Edad Media.

Como conclusión general, podemos decir que el Becerro de las Behetrías presenta una situación transicional sumamente compleja, que no admite ser caracterizada ni como plenamente arcaica ni como totalmente novedosa. Cada lugar y cada rasgo necesitan un estudio en su propio contexto para determinar, si ello es posible, la dinámica de la que forman parte. En cualquier caso, a pesar de las dificultades de este tipo de trabajo es evidente que la riqueza de la fuente es enorme y la luz que arroja sobre la evolución de esta comarca justifica plenamente el esfuerzo. 


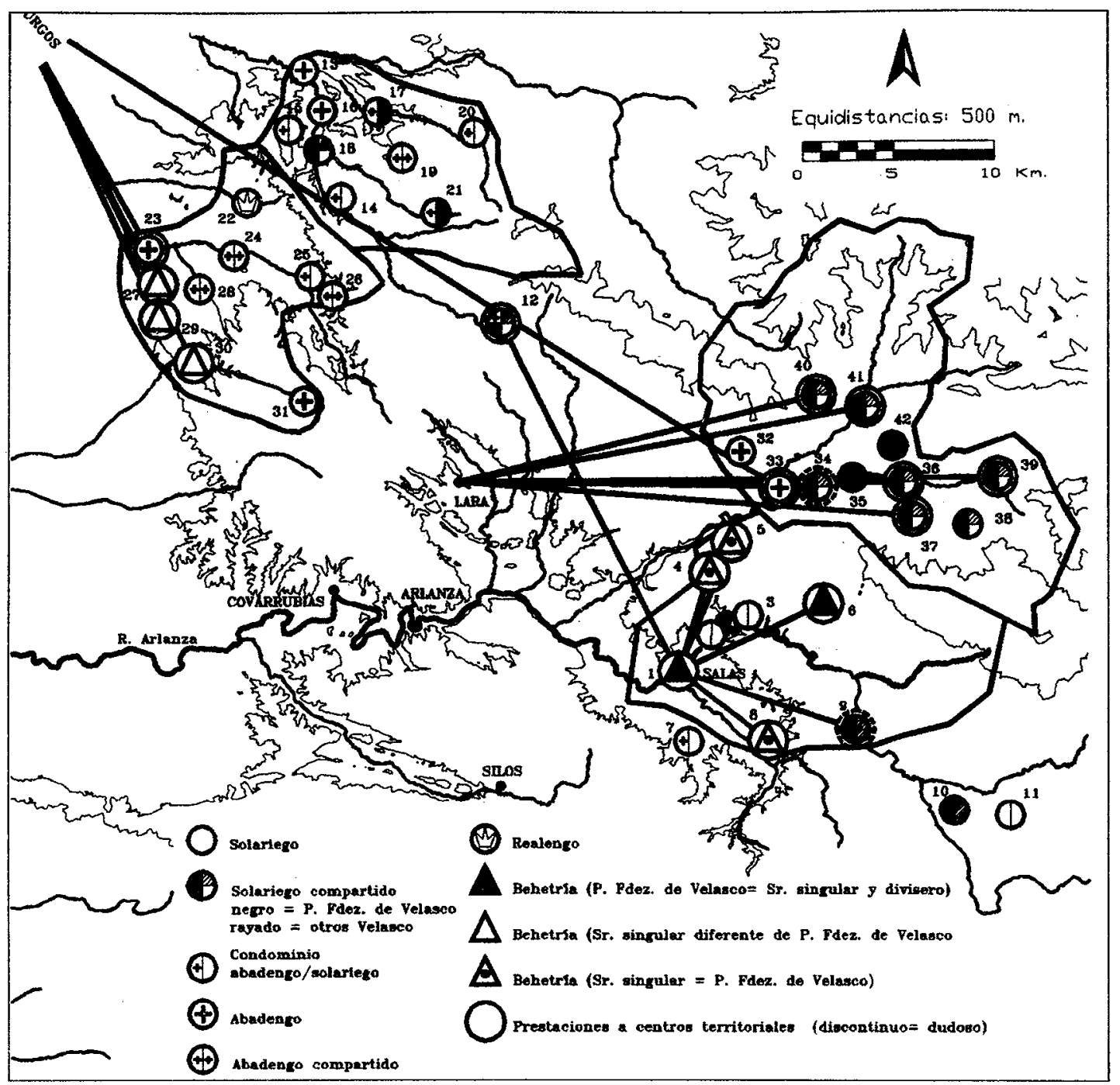

\section{LUGARES REPRESENTADOS EN EL. MAPA}

\section{Sector de Salas de los Infantes}

1. Salas de los Infantes: Behetría (Señor singular y natural: Pedro Fernández de Velasco)

2. Castrovido: Solariego de doña Sancha de Haro y Juan Díaz de Rocaful.

3. Terrazas: Solariego de doña Sancha de Haro y Juan Díaz de Rocaful.

4. Arroyo de Salas: Behetría (Señor singular: Pedro Fernández de Velasco)

5. Hoyuelos de la Sierra: Behetría (Señor singular: Pedro Fernández de Velasco)

6. Monasterio de la Sierra: Behetría (Señor singular y natural: Pedro Fernández de Velasco)

7. Hacinas: Solariego del monasterio de Fuencaliente, hijos de Juan Martínez de Avellaneda y de la viuda de Juan Martínez de Leyva.

8. Castrillo de la Reina: Behetría (Señor singular: Pedro Fernández de Velasco)

9. Hornillos: Solariego de Pedro Fernández de Velasco y Diego Pérez Sarmiento por su mujer, María de Velasco.

10. Palacios de la Sierra: Solariego de do Mayor de Castañeda, doña María de Velasco y Pedro Fernández de Velasco.

11. Vilviestre del Pinar: Solariego de doña Sancha de Haro y Juan Díaz de Rocaful. 
12. Villamiel de la Sierra: Abadengo de Remizo y solariego de la mujer de Juan Rodríguez de Sandoval, de doña María de Velasco, de la esposa de Sancho Martínez de Leyva y de Pedro Fernández de Velasco.

\section{Sector de Juarros}

13. San Andrés de Ibeas: Abadengo de San Cristóbal de lbeas

14. Mozoncillo de Juarros: solariego de Gómez Carrillo y abadengo de San Cristóbal de Ibeas.

15. Espinosa de Juarros: solariego de Juan Estévanez y abadengo de San Cristóbal de Ibeas.

16. Cuzcurrita de Juarros: Abadengo de San Cristóbal de Ibeas.

17. Salguero de Juarros: Solariego de Pedro Fernández de Velasco y abadengo de San Cristóbal de lbeas.

18. Cueva de Juarros: solariego de Juan Estévanez y Pedro Fernández de Velasco y abadengo de Remizo.

19. San Adrián de Juarros: Abadengo de San Juan de Burgos y de San Cristóbal de Ibeas.

20. Brieva de Juarros: solariego de Pedro Fernández de Velasco y abadengo de Las Huelgas y Villalbura.

21. Santa Cruz de Juarros: solariego de Pedro Fernández de Velasco y abadengo de Las Huelgas, San Cristóbal de lbeas y Bujedo.

\section{Sector de Ausín}

22. Modúbar de San Cebrián: Realengo.

23. Revillarruz: Abadengo del Obispo de Burgos

24. Los Ausines: Abadengo del Obispo de Burgos y de Santa Apolonia de Los Ausines

25. Revilla del Campo: Abadengo de Las Huelgas y solariego de Gómez Carrillo.

26. Revilla de la Fuente: Abadengo de San Cristóbal de Ibeas y de Bujedo.

27. Hontoria de Yuso: Behetría (Señor singular: doña Urraca, esposa de Pedro Ruiz Carrillo)

28. Quintanaseca: Abadengo de San Quirce y del monasterio de Ausín.

29. Hontoria de la Cantera: Behetría (Señor singular: Pedro Ruiz Carrillo)

30. Cubillo del Campo: Behetría (Señor singular: Pedro Ruiz Carrillo)

31. Cubillo del César: Abadengo de Las Huelgas

\section{Sector de Valdelaguna}

32. Villa Sarracín: Abadengo de San Pedro de Arlanza.

33. Barbadillo del Pez: Abadengo de Covarrubias.

34. Quintanilla de Urrilla: Solariego de Pedro Fernández de Velasco, doña María (su hermana), Juan Sánchez de Velasco y los hijos de Gómez Carrillo.

35. Vallegimeno: Solariego de Pedro Fernández de Velasco y Diego Pérez Sarmiento por doña María, su mujer.

36. Huerta de Abajo: Solariego de Pedro Fernández de Velasco, doña María (su hermana), Juan Sánchez de Velasco, los hijos de Gómez Carrillo y los hijos de Juan Martínez de Leyva.

37. Tolbaños de Abajo: Solariego de Pedro Fernández de Velasco, doña María (su hermana), Juan Sánchez de Velasco, los hijos de Gómez Carrillo y los hijos de Juan Martínez de Leyva.

38. Tolbaños de Arriba: Solariego de Pedro Fernández de Velasco, doña María (su hermana), Juan Sánchez de Velasco y los hijos de Juan Martínez de Leyva.

39. Huerta de Arriba: Solariego de Pedro Fernández de Velasco, doña María (su hermana), los hijos de Gómez Carrillo y los hijos de Juan Martínez de Leyva.

40. Riocavado: Solariego de Pedro Fernández de Velasco, doña María (su hermana), Juan Sánchez de Velasco, los hijos de Gómez Carrillo y los hijos de Juan Martínez de Leyva.

41. Barbadillo de Herreros: Solariego de Pedro Fernández de Velasco, doña María (su hermana), Juan Sánchez de Velasco, los hijos de Gómez Carrillo y los hijos de Juan Martínez de Leyva

42. Bezares: Solariego de Pedro Fernández de Velasco. 